\title{
Figurilla Antropomorfa Vaccea de Barro ${ }^{1}$
}

\author{
Juan Francisco Blanco García \\ Universidad Autónoma de Madrid
}

\section{Resumen}

El propósito de este artículo es dar a conocer una figurilla de barro antropomorfa hallada en el enclave vacceo de Cauca (Coca, Segovia). Apareció hace unos años entre fragmentos de adobes que se cocieron por causa de un incendio y entre los que se encontraban abundantes restos cerámicos. Posiblemente se trate de un exvoto o un oficiante, más que de un juguete infantil, aunque no sabemos si masculino o femenino porque carece de indicaciones sexuales. Su cronología podría situarse en los siglos II-I a. C.

PALABRAS CLAVE: Figura de barro, Religiosidad, Edad del Hierro, Vacceos, Cauca, provincia de Segovia, España.

\begin{abstract}
The aim of this paper is to present a human clay figure found in the vaccaean city of Cauca (Coca, Segovia). Was recuperated with sun-dried bricks belonging to a vaccaean edification and many fragments of wheel-turned pottery. Posibly it's an ex-voto or a priest, rather that a toy, because there are various figurines like this founds in iberic sanctuaries of the south and east of Iberian Peninsula. On the other side, there are no representation of sexual details and by this reason we don't know if is a female figure or a man figure. About the chronology, perhaps was in use in $2^{\text {nd }}$ or $1^{\text {st }}$ century B.C.
\end{abstract}

KEY WORDS: Clay figure, Religion, Iron Age, Vaccaean peoples, city of Cauca, Segovia province, Spain.

Las representaciones antropomorfas en el mundo vacceo son ciertamente escasas y por ello, excepcionales. Pintadas en vasos cerámicos, grabadas en soportes metálicos o modeladas en arcilla, la mayor parte de las que se conocen actualmente han sido halladas fuera de contexto $\mathrm{y}$, por tanto, su valor como documento para profundizar en el conocimiento de la sociedad vaccea, de su mentalidad mágico-religiosa o, sencillamente, de su vida cotidiana, queda sensiblemente mermado. Este es el caso de la figurita que ha motivado estas páginas. Fue hallada hace años en el área de

1 Este trabajo ha sido realizado en el marco del Proyecto de Investigación de I+D+i (2004-2007) Vacceos: identidad y arqueología de una etnia prerromana en el Valle del Duero
Los Azafranales, la única zona de Cauca vaccea que hoy se encuentra sin construir, durante la realización de una zanja con máquina retroexcavadora y parece ser que a unos tres metros de profundidad respecto a la superficie actual (Figura 1). Por los datos que hemos podido recabar, apareció junto a numerosos fragmentos de adobes requemados de dimensiones grandes que, en esta zona, indudablemente tuvieron que pertenecer a una edificación vaccea de similares características constructivas a otras documentadas con anterioridad en la zona (Blanco García, 1992; Pérez

(HUM2006-06527/HIST), de la Dirección General de Investigación del Ministerio de Educación y Ciencia. 


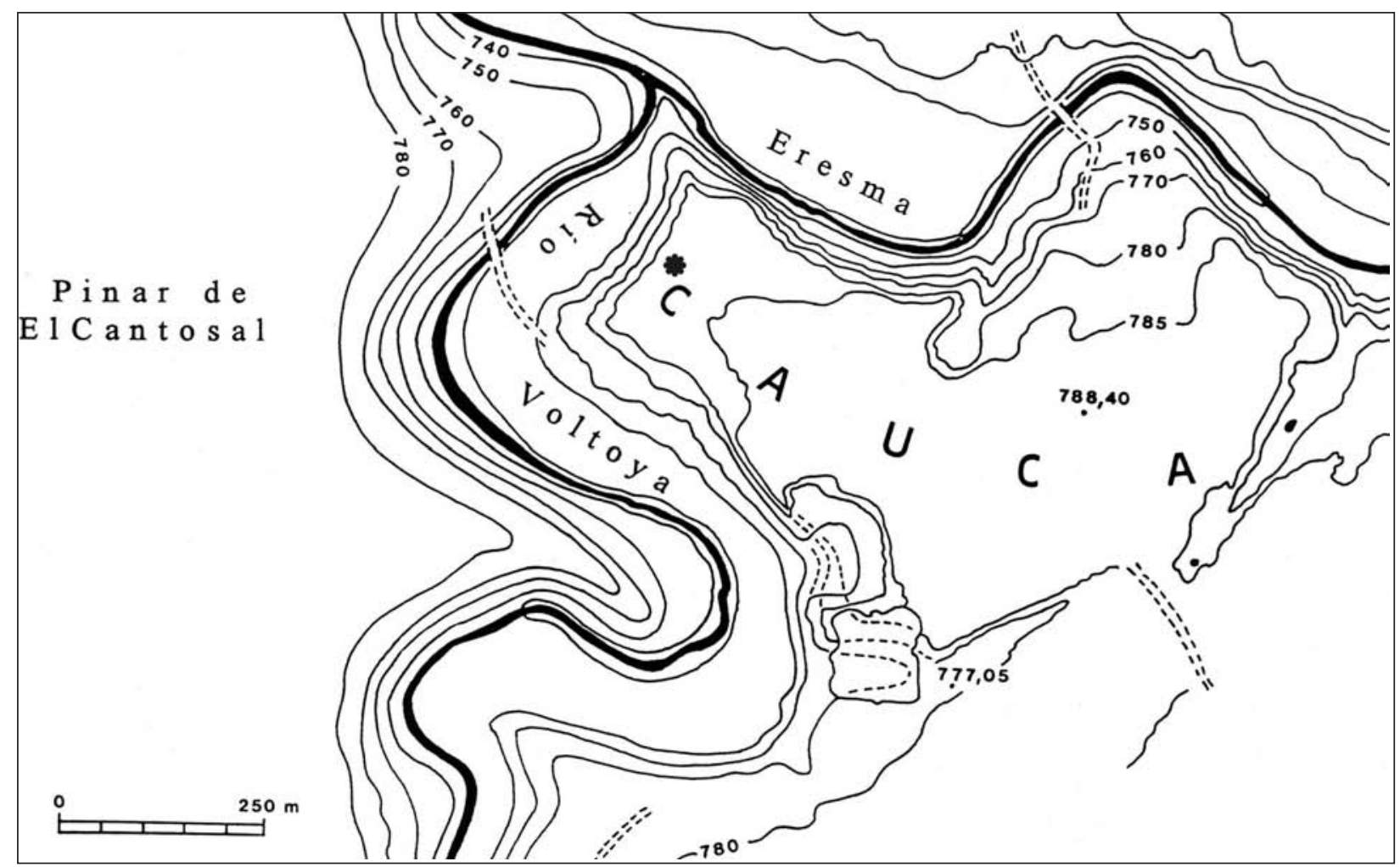

Figura 1. Lugar de aparición de la figura (asterisco) en el mapa topográfico de Cauca.

González y Blanco García, 2000: 42-44). Mezclados con los adobes parece ser que abundaban los fragmentos de vasos cerámicos, de los que lamentablemente no se recogió ninguno pero que hubieran sido definitorios para aproximarnos con cierta seguridad a la cronología del conjunto y por ende a la de la figura.

\section{Descripción de La PIEZA}

La figurilla ha sido modelada en arcilla depurada pero de calidad algo inferior a la que nos tienen acostumbrados los ceramistas vacceos cuando fabrican muchas de las denominadas producciones singulares como las cajitas excisas y lisas, las sonajas, los pies votivos, buena parte de las figurillas zoomorfas, etc. El procedimiento de elaboración es tan sencillo que no guarda ningún secreto: a partir de un cilindro macizo de barro, y con los dedos, el artesano ha aplanado la parte superior de la cabeza, destacado la nariz por pellizco entre dos grandes cuencas oculares, también por el mismo procedimiento ha obtenido las orejas, y en la base ha hecho sobresalir dos pequeños apéndices a modo de pies que actualmente no se conservan pero cuya sección ovalada es delatada por las roturas que han quedado (Figuras 2-5).
Una vez modelada, las superficies han sido simplemente alisadas pero no de una forma homogénea, sino algo irregular, como consecuencia de lo cual, y con ayuda de una lupa, en algunas zonas se pueden observar impresas las huellas dactilares del artífice. No ha habido, por tanto, un trabajo de bruñido para dar mayor realce visual y táctil a la pieza y tampoco se ven restos de pinturas con las que se podían haber añadido detalles anatómicos o de la vestimenta como ocurre en muchas de las terracotas ibéricas. Su coloración rojo ladrillo delata que fue cocida en atmósfera oxidante y la zona levemente negruzca que presenta en la parte delantera lo más probable es que se haya producido con posterioridad al momento de su cocción, quizá cuando la pieza ya estaba amortizada o durante el incendio de la referida construcción que coció los adobes con los que compartía contexto.

Sus dimensiones son pequeñas, pues tan sólo tiene $97 \mathrm{~mm}$ de altura máxima, $47 \mathrm{~mm}$ de anchura máxima (en la cabeza), entre 33 y $35 \mathrm{~mm}$ de sección a la altura del cuello y entre 40 y $45 \mathrm{~mm}$ de sección a la altura de los pies. La oscilación en ambas secciones se debe a que no se trata de un cilindro perfecto, como puede suponerse en este tipo de elaborados manuales, sino irregular. Por 


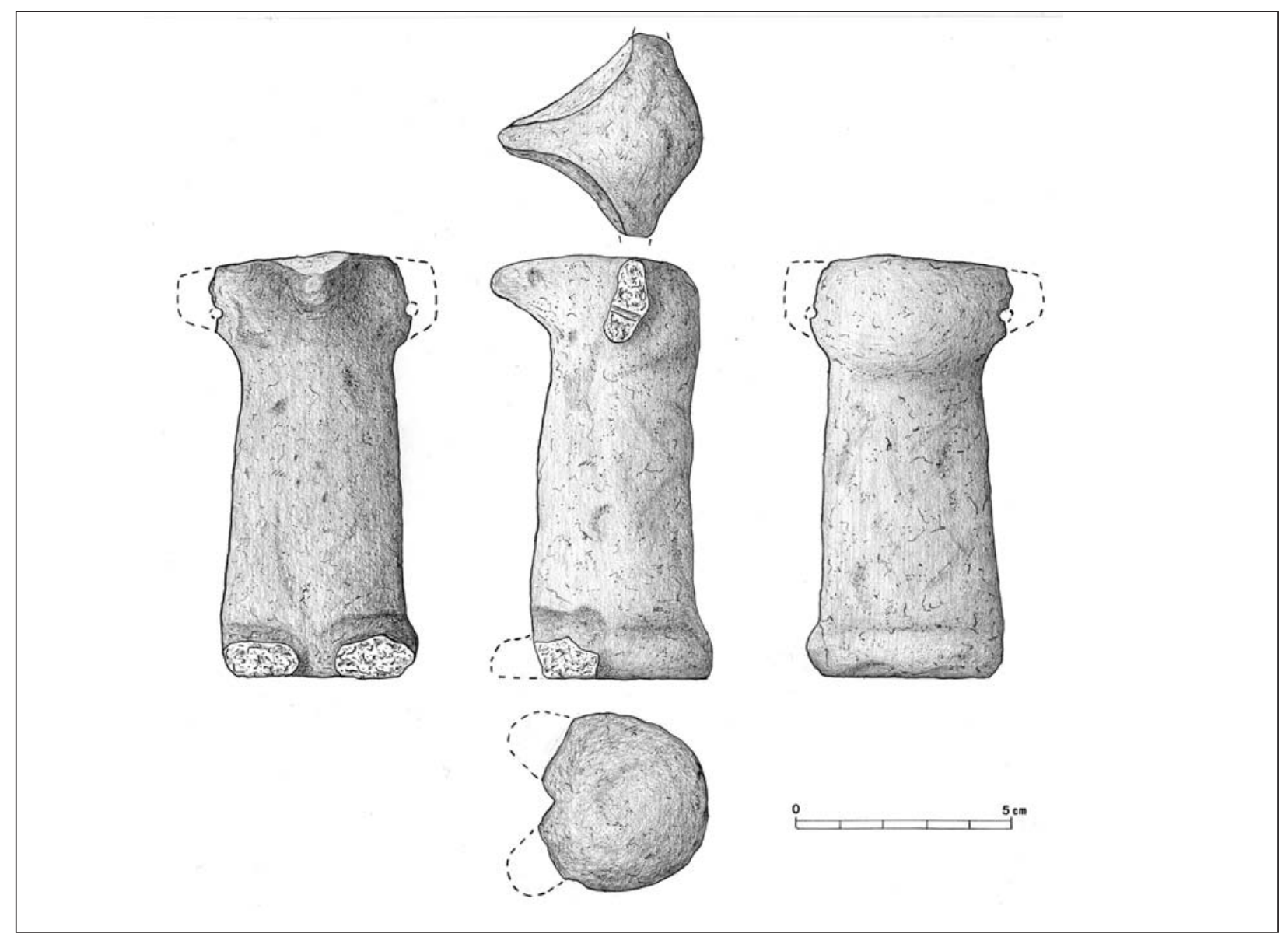

Figura 2. Diversas vistas de la figura.

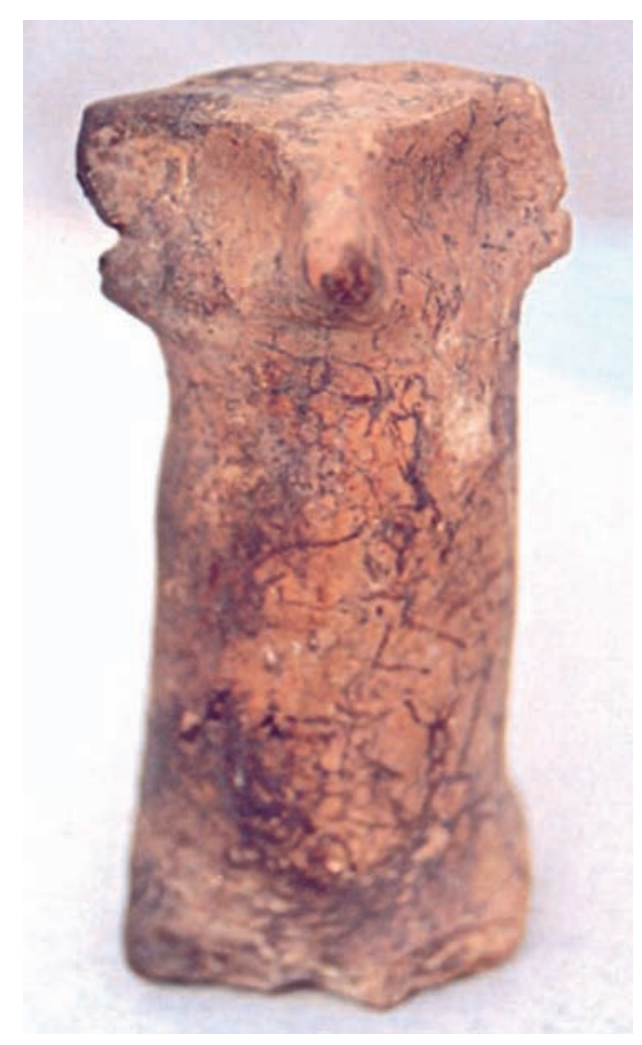

Figura 3. Vista frontal.

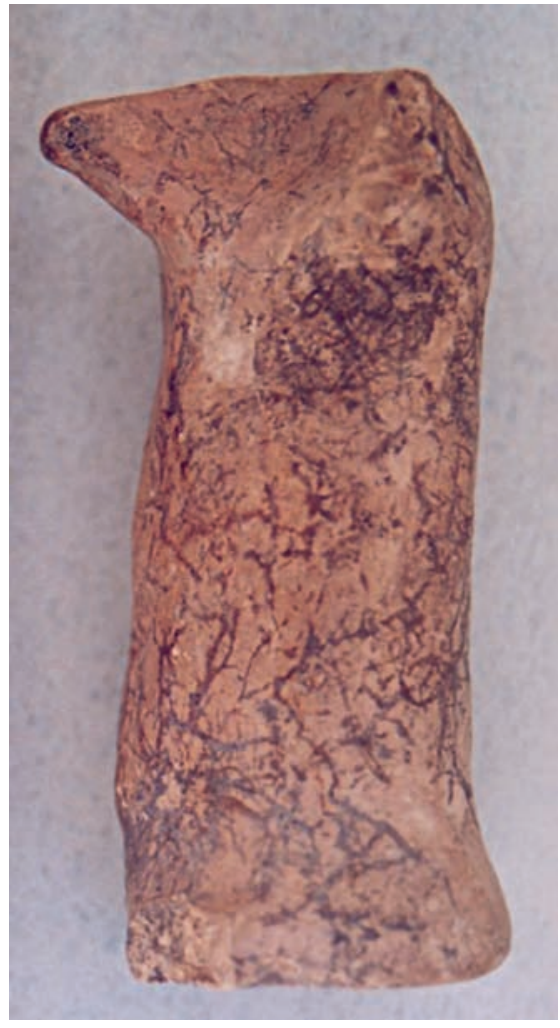

Figura 4. Perfil izquierdo. 


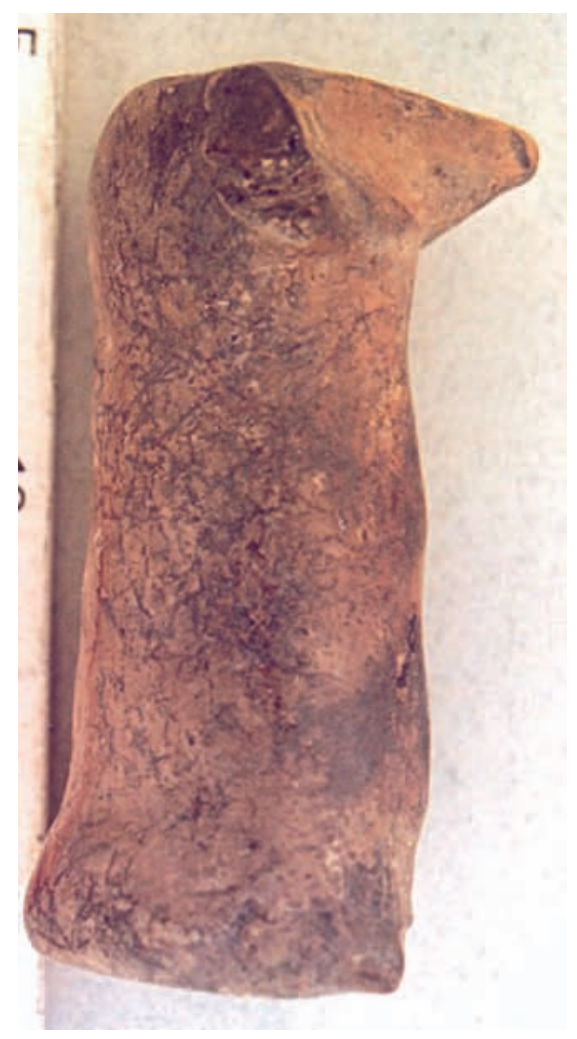

Figura 5. Perfil derecho.

otro lado, esos $47 \mathrm{~mm}$ de anchura máxima en la cabeza fue mayor en origen si consideramos que ha perdido la parte más sobresaliente de las orejas, con lo que su anchura real, cuando la figura estaba completa, hubo de ser de unos $58 \mathrm{~mm}$. La base también fue en origen algo más amplia, pues, como decimos, ha perdido los dos pies que tuvo $y$, aunque seguramente no mucho, sobresalieron respecto a la verticalidad del cuerpo. A pesar de su extremo esquematismo, se trata de una figura humana completa, no de un ídolo-cabeza como podría parecer a primera vista y si reparamos en cierto tipo de figuritas ibéricas también de barro formadas sólo por la cabeza y un largo cuello cuya base sirve de apoyo (Aranegui, Mohen y Rouillard, 1998: 313, n 238). Las dos roturas de sección ovalada que se observan en la parte anterior de la base del idolillo, pertenecientes a los referidos pies, aunque debieron de sobresalir poco, contribuyeron a una mayor estabilidad de la pieza en el mantenimiento de su posición vertical. Quizá esto mismo, afianzar la verticalidad, es lo que se haya querido conseguir con el suave engrosamiento de la base en su parte posterior y en los laterales, pero nos parece más atractiva y verosímil otra interpretación de dicho abultamiento: que realmente se trate del borde inferior recogido de una especie de manto largo, bajo el cual sobresa- len únicamente la mitad anterior de los pies, algo que resulta bastante común en representaciones de bulto alusivas a divinidades, sacerdotes, personajes de élite, etc. de casi todas las culturas mediterráneas (Figura 6). De ser esto así, estaríamos ante una figura no desnuda, como otras prerromanas peninsulares de las que luego hablaremos, sino con el cuerpo íntegramente cubierto por un manto, y esa sería la razón por la cual no se ha consignado ningún detalle relativo al sexo, y el responsable de que no sepamos si se trata de una imagen masculina o femenina. Las figuras humanas cubiertas con manto largo son muy corrientes en el mundo ibérico y en la propia meseta viene al caso recordar idolillos tan conocidos como el recuperado en el yacimiento burgalés de La Llana, en Castrillo de la Reina (Esparza Arroyo, 1988: 134-136, lám. V), de cabeza cubierta con capuchón apuntado y cuerpo acampanado como consecuencia del manto que lo cubría y que en alguna ocasión se le ha querido identificar con un sacerdote, o el de Langa de Duero (Taracena, 1932: 56-57, fig. 12), también de cuerpo entero pero troncocónico y de ejecución muy burda que el propio Taracena interpretaba como una mujer tocada con mitra al estilo de ciertos exvotos ibéricos.

Volviendo a la figura de Coca, la cabeza ha sido modelada mediante varios pellizcos para destacar la prominente nariz puntiaguda entre anchas cuencas oculares y para individualizar las orejas. Aunque éstas se encuentran rotas, como se ha señalado, estaban horadadas transversalmente, y lo más probable es que hubieran llevado algún tipo de pendiente. Analizadas con detenimiento dichas perforaciones para ver si quedaban restos o marcas de la materia de la que podían haber esta-

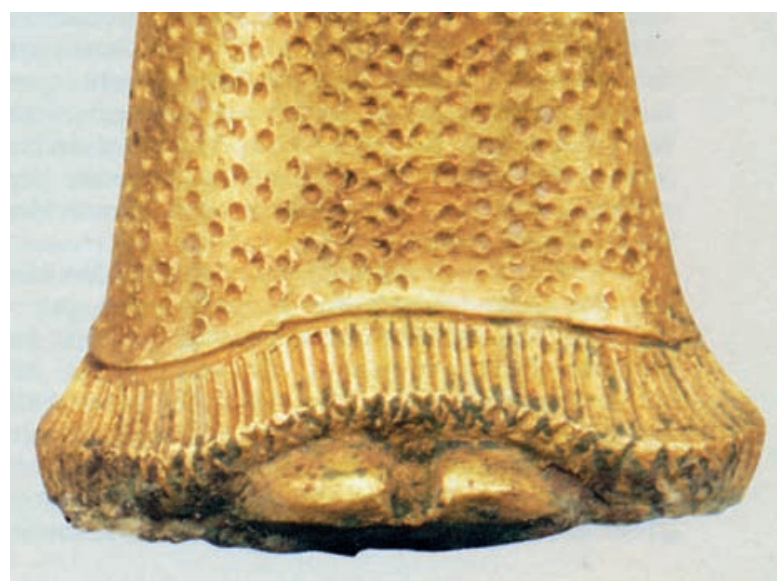

Figura 6. Ejemplo de borde inferior abultado de manto bajo el que sobresalen los pies. 
do hechos los intuidos pendientes, no conseguimos identificar nada. Las posibilidades son varias: desde simples aretes metálicos o colgantes de formas algo más complejas -de bronce, hierro o algún metal noble-, hasta cuentecitas ensartadas en un pasador -de cuerda, hilo de cuero, pelo trenzado, alambre de bronce- que se haría pasar por los agujeros. Lo más probable es que llevara anillitas metálicas, tal como las vemos adornando las orejas de algunas cabecitas de los báculos o estandartes celtibéricos (Jimeno Martínez et alii, 2004: 163, fig. 122, b, fig. 123, e y lám. XIII, 3; Jimeno Martínez, 2005: no 213 del catálogo). Es más, seguramente las orejas se encuentran rotas por la zona del orificio precisamente al haber sido arrancadas violentamente tales anillas en época vaccea, pues las roturas, al igual que las de los pies, son antiguas. Lo que parece prácticamente descartable es que los pendientes hubieran sido de arcilla también, a modo de las anillas que penden de las asas de algunos recipientes cerámicos vacceos (Schüle, 1969: taf. 165, 4 y 5; Romero Carnicero, 1991: 88-89), pues la propia estrechez de las horadaciones haría difícil su instalación y se vería considerablemente mermada su movilidad, que es en definitiva la gracia de los pendientes.

Mientras la parte superior de la cabeza es plana, lo cual nada tiene de peculiar en figuritas celtibéricas e ibéricas de este tipo, como luego veremos, la posterior es suavemente convexa para marcar con claridad la diferencia entre la cabeza y el cuerpo. De lo que no se han consignado detalles es de la boca, de los ojos propiamente dichos, de las fosas nasales y del mentón.

\section{CONSIDERACIONES}

Con ser esta una pieza excepcional, no es la primera figurilla antropomorfa prerromana que aparece en Cauca y su entorno, pues ya en 1936 Julio Barrientos publicó una cabecita, también de barro, que hoy se encuentra en paradero desconocido (Barrientos, 1935-36: lám. IV; Barrio Martín, 1994: 413-415, fig. 4, b; Id., 1999: 116, fig. 75, sup. izq.), y hace casi dos décadas nosotros mismos dimos a conocer un pequeño exvoto de bronce, de cuerpo entero, hallado en el barrio caucense de la Cuesta del Mercado que lamentablemente ha corrido la misma suerte que aquélla (Blanco García, 1994: fig. 24, 3; Barrio Martín, 1999: 116, fig. 75, inf. dcho.). Aunque podría venir al caso, no creemos que en la pella de barro cilíndrica con impresiones de dedos a modo de cuencas oculares recuperada en el alfar vacceo de Coca que excavamos hace unos años existiese la intención de conseguir una cabeza humana (Blanco García, 1998b: fig. 13, 2). La alta cronología de esta instalación respecto a lo que constituye el fenómeno del figurativismo en el ámbito vacceo, la existencia de un par de huellas a cada lado de la pieza -lo que la convertiría en una insólita doble cara- y el hecho de que ésta no sea la única pella con marcas de dedos recuperada, nos sugieren no considerarla como representación antropomorfa. Todo ello a pesar de que en Numancia existe una figurilla prácticamente idéntica a ella (Jimeno Martínez, 2005: no 107 del catálogo), si bien es más moderna que la del alfar caucense, y en este caso sí parece haber existido una intención de conseguir un antropomorfo.

Sin salir de la provincia de Segovia, la única figura humana fabricada en arcilla que conocemos es el idolillo de la colección Rotondo recuperado en fecha incierta en el término municipal de Carabias (Figura 7) (Gil Farrés, 1951; Barrio Martín, 1994: 415-417, fig. 4, a) y que hoy sabemos positivamente que procede del importante
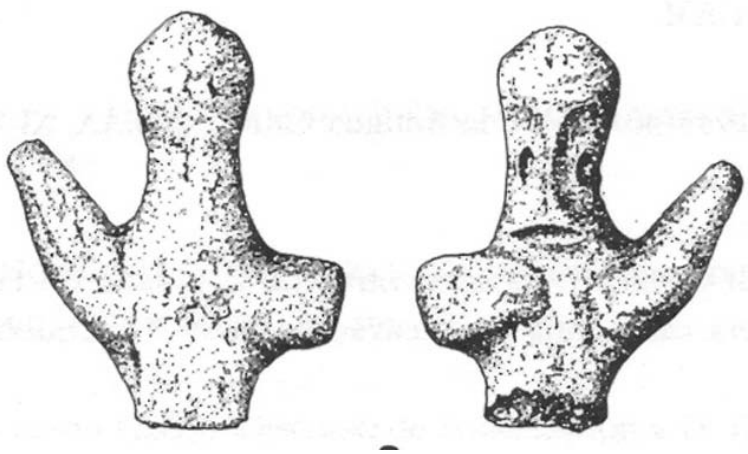

Figura 7. Idolillo de la Colección Rotondo, procedente del poblado de Los Quemados I en Carabias (según Barrio Martín, 1994).

poblado de Los Quemados I (Blanco García, 1998a: fig. 19, $\mathrm{n}^{\circ} 14 ;$ Id., 2006: 39 y 72 , fig. $1, \mathrm{n}^{\circ}$ 19; López Ambite, 2008: 89-94, fig. 8), situado en un espacio fronterizo entre el mundo vacceo y el celtibérico. Esta es una figura que se conserva sólo de cintura hacia arriba pero que ofrece más detalles anatómicos y faciales que la de Coca, pues han sido representados brazos, ojos y boca. Su cabeza responde a un tipo característicamente celtibérico del que en yacimientos próximos, como Carratiermes, hay ejemplares similares (Argente, Díaz y Bescós, 2001: 195, figs. 67 y 68, 
2; Jimeno Martínez, 2005: no 279 del catálogo). Y la peculiaridad de representarlo con el brazo izquierdo levantado y el derecho sobre el pecho no parece casual o ingenua, sino que seguramente tenga un significado de carácter mágico-religioso, pues la encontramos también en una figurita femenina de barro recuperada en el depósito votivo del Cerro do Castelo de Garvão, si bien en este caso es el brazo derecho el que se levanta y el izquierdo al estar roto no sabemos qué posición adoptaría (Beirão et alii, 1985-86, 212, fig. 5). El depósito portugués se fecha en los siglos IV-III a. C. y de la figura segoviana, al haber sido hallada en superficie, desconocemos su cronología, pero es posible que fuese de época algo más avanzada. Con independencia de la cronología, en ambos casos la posición que adoptan los brazos parece estandarizada y nos remiten a representaciones divinas y exvotos ibéricos y púnicos, a su vez receptores de una larga tradición mediterránea que se remonta, cuando menos, a la Edad del Bronce de ciudades próximo-orientales y chipriotas como Ugarit (Saadé, 1979) o Enkomi (Catling, 1964), respectivamente, por lo que perfectamente podría tratarse de representaciones de oficiantes religiosos, orantes, suplicantes, exvotos o incluso personajes divinos. No obstante esto, que es la hipótesis que más nos convence, cabrían otras posibilidades, tales como que el ídolo de Carabias no fuera realmente una figura humana individual y exenta, sino de un jinete cuyo caballo no se ha conservado, que hubiera sido un remate decorativo aplicado al borde de un vaso o el asidero de una tapadera. Respecto a lo primero, si la desestimamos como jinete es atendiendo a que, por regla general, cuando éstos aparecen representados en las fíbulas de caballito, por ejemplo, o en los estandartes, los brazos siempre están en posición tendente hacia abajo o hacia el frente, hacia el cuello del équido (Almagro-Gorbea y Torres, 1999: 119-122, figs. 10 y 11), no uno en alto y el otro cruzado sobre el pecho. Como remate decorativo del borde de algún vaso, en cuyo caso sería un vaso especial, estaríamos ante un ejemplo hasta ahora único en el mundo meseteño, pues no se trata de una simple cabeza aplicada. Finalmente, las asitas figuradas de tapaderas no suelen ser antropomorfas, sino zoomorfas, en unos casos se trata de figuras completas y en otros sólo cabezas, y las especies más representadas son diversos tipos de aves, felinos, cápridos, etc.

Por otro lado, salvo en lo que se refiere a la técnica del modelado de la cabeza, por pellizco, en poco se parece esta pieza de Carabias a la caucense. Como tampoco tienen mucho que ver formalmente con ella la cabecita recuperada en el nivel VII del sondeo efectuado en 1965 en Simancas por Federico Wattenberg (1965: 12-14, fig. 6), también vaccea, por tanto, pues dista de la caucense en muchos aspectos: es esférica, no pseudocilíndrica; en la base tiene un orificio que induce a pensar que en origen estuvo sujeta a otro elemento, quizá el resto del cuerpo, que seguramente también sería de barro, con lo que cabeza y cuerpo se modelaron aparte; posee detalles que en la caucense no existen, como la incisión que bordea la frente y cierra por atrás a un nivel más bajo, por lo que tal vez sea la representación de una diadema, o esa especie de moño con coleta que cae desde lo más alto de la bóveda craneal, también realizado con incisiones rectas hechas a tirón. En lo único que coinciden ambas figuras es en la forma en la que han sido modeladas las cuencas oculares y la nariz, pues están realizadas por pellizco y en ninguno de los casos se han detallado los ojos.

Para encontrar una figura no sólo similar a la caucense, sino seguramente idéntica en origen, pues sólo se conserva un fragmento de la cabeza (Figura 8), hemos de fijar nuestra atención en la necrópolis vallisoletana de Las Ruedas. De nuevo Pintia y Cauca aparecen estrechamente ligadas como si de dos ciudades vacceas hermanas se tratara, al menos en lo que a su cultura material se refiere. La figurita de Las Ruedas, recuperada en posición secundaria, debido a los escasos rasgos definitorios que presentaba fue identificada por Carlos Sanz como parte de una esquemática cabeza "...quizás más zoomorfa que humana..." (Sanz Mínguez, 1997: 337, 175, nº 543, fig. 171, 543), aunque la analiza en el epígrafe idolillo cilíndrico y no en el de figuras zoomorfas, lo que indica el grado de dificultad que existe para interpretar la pieza. En realidad, y gracias a la figura completa de Coca, hoy podemos decir que la pintiana es también humana y corresponde exactamente a la mitad derecha de la cabeza caucense. Lo que C. Sanz describe como "...pico central, horadado transversalmente..." pertenece a la oreja izquierda perforada, de la que seguramente colgó un pendiente tampoco sabemos de qué materia. Y lo que este autor describe como "...dos aletas laterales y una cresta posterior.", realmente son, una de ellas, la nariz prominente, aunque algo deteriorada, y la otra, la zona posterior de la cabeza. Cabeza que, por otra parte, y al igual que en Coca, tiene la bóveda craneal plana. Al estar 


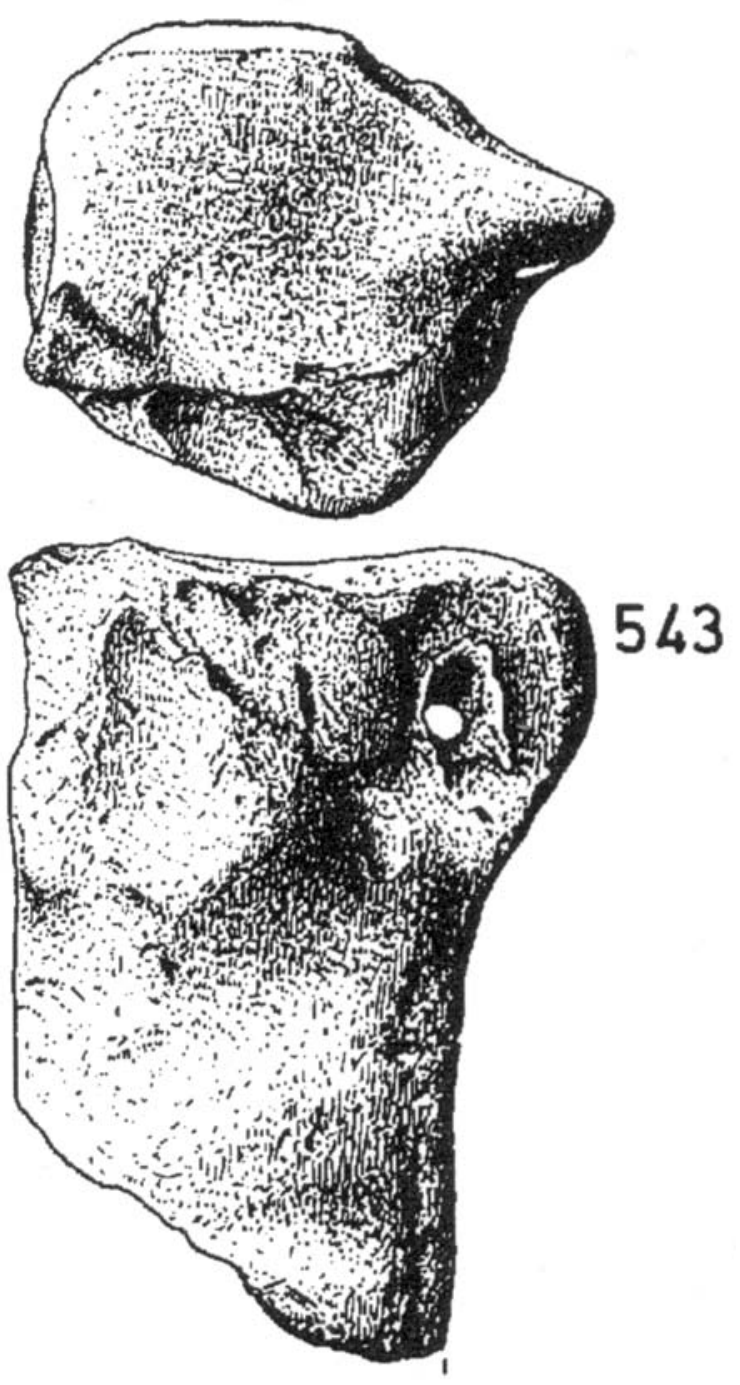

Figura 8. Fragmento de idolillo recuperado en la necrópolis de Las Ruedas/Pintia (según Sanz Mínguez, 1997).

partido el cilindro que hace las veces de cuerpo y no conservarse la base, desconocemos si pudo haber tenido pies como ocurre en la de Coca, y tampoco sabemos si también se insinúa esa especie de manto que proponemos y que impide saber el sexo.

Ante figuras de este tipo, una de las primeras interrogantes que surgen es la de su funcionalidad. Cuando tuvimos ocasión de verla, algo que de inmediato comprobamos era si no habría servido como machacador o triturador, pues la base era plana y, con independencia de su antropomorfismo, era un objeto que pesaba más de lo que aparentemente cabía esperar y ello era debido a que había sido fabricado con una masa arcillosa muy densa, poco porosa, por lo que bien podrían haberse realizado con él labores de golpeo o trituración de materias no excesivamente duras, ya que no deja de ser barro. Pues bien, la base de la figura no mostraba el más leve indicio de haberse realizado con ella tales trabajos: ni golpes ni rozaduras, salvo la circunstancia de que los dos pequeños pies que tuvo se habían roto. Estos mismos pies hacían precisamente inviable la hipótesis de que se tratara de una macita antropomorfa. Si contemplamos la posibilidad de que pudiera haber sido utilizada como mano de mortero era sencillamente porque tanto en el mundo prerromano meseteño como en el ibérico se conocen piezas parecidas en tamaño y forma que han sido interpretadas como machacadores. En una de las sepulturas de la necrópolis de Aguilar de Anguita, por ejemplo, se recuperó, como parte del ajuar, una figurita de barro muy parecida a la caucense en dimensiones, aunque de sección cuadrada (Figura 9), rematada en cabeza de ave que algunos autores han interpretado como mano de mor-

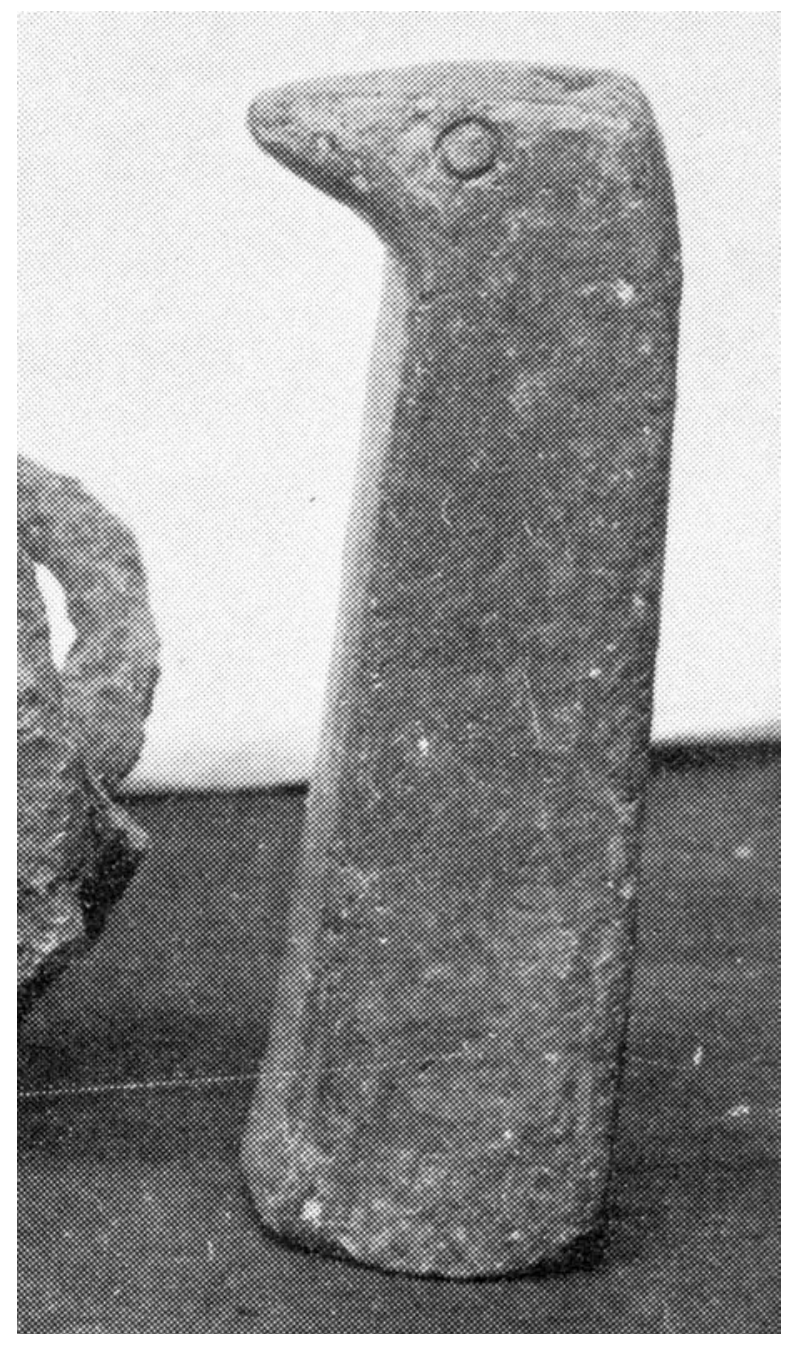

Figura 9. Figurita de barro con cabeza de ave recuperada en una de las sepulturas de Aguilar de Anguita (Guadalajara) (Aguilera y Gamboa, 1911; Cabré, 1988). 
tero (Aguilera y Gamboa, 1911, III: fig. XXIV, 2 y lám. XXIV, 1; Cabré, 1988: fot. de p. 124; Ead., 1990: 212, fig. 10, extremo dcho.) $)^{2}$. En varios yacimientos ibéricos, como por ejemplo Serra de 1’Espasa (Vilaseca, 1947: lám. XXI, 1), Coímbra del Barranco Ancho (Molina, Molina y Nordstrom, 1976: 61, fig. 38, lám. XIX, 3), Cova de Les Maravelles (Aparicio et alii, 2005: 202, fig. 55, inf. izq.) o el albacetense de El Amarejo (Broncano y Blánquez, 1985: 129 y 195, fig. 56, 94 y fig. 102, 174), también se han recuperado figuras de aspecto antropomorfo hechas de barro y dimensiones en torno a los $10 \mathrm{~cm}$ de altura que han sido usadas como machacadores. Con independencia de tal función, no hay ninguna duda de que estas piezas tuvieron un carácter simbólico, como viene demostrado por la comparecencia de algunas de ellas en el interior de sepulturas: en la número 63 de la necrópolis murciana de El Poblado, por ejemplo, perteneciente a una niña, se recuperó una con los apéndices horadados que ha sido interpretada como juguete (Page et alii, 1987: 30, fig. inf. de p. 31; García Cano, 1997: 192-193, fig. 84-2, no 5649; García Cano et alii, 2008: 81, 304, fig. 103, 2 y 437, lám. 16; Chapa, 2003: 128 , fig. $\left.13, n^{\circ} 5649\right)$. A diferencia de nuestra figurita y la de Las Ruedas o la de Aguilar de Anguita, las ibéricas carecen de cabeza y de la parte superior sobresalen dos apéndices a modo de brazos arqueados que son los que les dan ese supuesto perfil antropomorfo, y en virtud del mismo, ese carácter simbólico al que hemos aludido. Empleamos el término "supuesto" porque algún autor ha propuesto la idea de que esos apéndices pudieran ser cabecitas de ave contrapuestas más que brazos humanos.

Desestimada, por tanto, su uso como mano de mortero, únicamente nos quedaban dos posibles funciones: que hubiera sido un juguete infantil o una imagen de carácter mágico-religiosa (exvoto, sacerdote...). Al proceder de un contexto doméstico, pues como se ha dicho fue hallada entre los materiales de derrumbe de una edificación y numerosos vasos cerámicos rotos, perfectamente

2 A pesar de interpretarse funcionalmente de este modo, Alberto Lorrio refiere que es una pieza hueca en su parte inferior (Lorrio, 1997: 243), y, efectivamente, a la vista de la fig. XXIV no 2 de Cerralbo sí que se aprecia que la base está realizada en hueco, por lo que resultaría absolutamente inadecuada como mano de mortero.

3 Razón por la cual T. Moneo los interpreta como figuras "caricaturescas" de carácter popular, de amplia difusión podría haber formado parte del conjunto de enseres de una familia en el que los juguetes infantiles son parte constitutiva, pero por lo mismo también podría haber estado vinculada al ámbito de la religiosidad doméstica. Como juguetes algunos autores interpretan muchas de las figuritas de barro recuperadas en excavaciones de poblados meseteños, sobre todo las zoomorfas de factura tosca (AA.VV., 1912: 36; Wattenberg, 1963: 42; Galán Domingo, 1989-90: 188-189; Alonso y Benito, 1991-92: 534). Otros, por el contrario, han visto en ellas objetos de culto, votivos, sobre todo las humanas, que serían los equivalentes en barro de los exvotos broncíneos ibéricos, ya procediesen de contextos funerarios o habitacionales (Mélida, 1922: 120 y 274; Taracena, 1954: 279; Salinas de Frías, 1984-85: 84 y 85; Id., 1985: 317-318; Marco Simón, 1987: 68; Sopeña Genzor, 1987: 56; Lorrio, 1997: 334; Curchin, 2004: 192).

En la interpretación de la figura de Coca como posible objeto cultual, muy cercanos en lo que a los aspectos formales se refiere se encuentran algunos exvotos de barro, de bronce e incluso de piedra recuperados en yacimientos ibéricos. Del santuario de la Serreta d'Alcoi, por ejemplo, proceden varios exvotos-cabeza realizados en barro, muy toscos ${ }^{3}$, con la base terminada en punta, de los cuales uno de ellos guarda cierto parecido formal con la figura caucense, si bien en el centro de sus dos grandes cuencas oculares cóncavas se han señalizado los ojos mediante bolitas de barro pegadas (Juan i Moltó, 1987-88: 314-315, lám. VIII; Aranegui, Mohen y Rouillard, 1998: 313, $\mathrm{n}^{\circ}$ 238), tal como también muestran alguna terracotas púnicas (Almagro Gorbea, 1980: 71, 48, lám. XXXII). A diferencia de la pieza segoviana, en la alicantina la mayor parte del desarrollo cilíndrico corresponde al largo cuello, no hay indicios de que hubiera querido ser la representación de un esquemático cuerpo completo. Por el contrario, esto sí lo encontramos en algún que otro exvoto de bronce, aunque de dimensiones menores al nuestro, como bien ilustra uno de los recuperados

territorial en el mundo ibérico (Moneo, 2003: 365; AlmagroGorbea y Moneo, 2000: 48), desde Sevilla (Fernández, Chasco y Oliva, 1979: 60, fig. 37, 500-25 y lám. XII, 4) hasta el noreste peninsular (Garcés i Estallo, 1993), pasando por el Cabecico del Tesoro (Sánchez Meseguer y Quesada Sanz, 1991: 369, lám. 2, A) o la valenciana Cova de Les Maravelles (Aparicio et alii, 2005: 202, fig. 55, sup. izq.). 
en el Cerro de Alarcos, también con pequeños pies salientes en la base (Benítez de Lugo, Esteban y Hevia, 2004: fig. p. 79, 9) y en varios exvotos femeninos de piedra recuperados en el santuario ibérico cordobés de Torreparedones, igualmente con los pies sólo insinuados, como nuestra figura (Morena López, 1989: 62-63 nº 5, lám. XVII y $66, \mathrm{n}^{\circ} 16$, lám. XXVIII), si bien alguno de ellos es de dimensiones algo mayores que la pieza segoviana y que, por cierto, algunos de ellos también suelen tener el cuerpo cubierto por largo manto.

Resumiendo, parece posible que esta pequeña figura sea un exvoto o un oficiante de época avanzada, quizá de los siglos II-I a. C. apoyándonos en la tardía cronología del fenómeno figurativo en el ámbito vacceo, pues al desconocer las características del contexto no podemos ajustar el momento de su uso y amortización. El mayor interés que presenta es que, por ahora, son muy escasas las figuras humanas completas hechas en barro en la meseta prerromana, en general, y en el mundo vacceo, en particular, pues las que más se fabricaron fueron las zoomorfas (caballos, toros, cabras, jabalíes, etc.), y cuando se modelan antropomorfas suelen ser sólo cabezas, en unos casos de bulto y en otros aplicadas a vasos cerámicos. Por otro lado, la convivencia de restos de edificación, vasos cerámicos y figurita no es suficiente para demostrar que estemos ante un depósito votivo o los restos de un santuario, pues falta lo más importante: el registro en condiciones científicamente aceptables de todo el conjunto. Sólo así se podría haber llegado más lejos en su interpretación. Quién sabe si entre esos trozos de adobes y de recipientes no habrían fragmentos de más figurillas, antropomorfas y/o zoomorfas, y sólo se reparó en esta por estar completa.

\section{BIBLIOGRAFÍA}

AA.VV., 1912: Excavaciones en Numancia. Memoria presentada al Ministerio de Instrucción Pública y Bellas Artes por la Comisión Ejecutiva de las Excavaciones de Numancia. Madrid.

AGUILERA Y GAMBOA, E. de, 1911: Páginas de la Historia Patria por mis excavaciones arqueológicas. Tomos III (Aguilar de Anguita) y IV (Diversas necrópolis ibéricas y Drunèmeton). Inédito.

ALMAGRO GORBEA, M. J., 1980: Catálogo de las terracotas de Ibiza del Museo Arqueológico Nacional. Madrid.
ALMAGRO-GORBEA, M. y MONEO, T., 2000: Santuarios urbanos en el mundo ibérico. (Bibliotheca Archaeologica Hispana, 4). Madrid.

ALMAGRO-GORBEA, M. y TORRES, M., 1999: Las fíbulas de jinete y de caballito. Aproximación a las élites ecuestres y su expansión en la Hispania céltica. Zaragoza.

ALONSO, P. y BENITO, J. E., 1991-92: “Figuras zoomorfas de barro de la Edad del Hierro en la Meseta norte", Zephyrus, XLIV-XLV, 524-536. Salamanca.

APARICIO, J., MOROTE, J. G., SILGO, L. y CISNEROS, F., 2005: La Cultura Ibérica. Síntesis Histórica. Valencia.

ARANEGUI, C., MOHEN, J. P. y ROUILLARD, P. (coms.), 1998: Los Iberos. Príncipes de Occidente. Catálogo de la Exposición (Barcelona, 1998). Barcelona.

ARGENTE, J. L., DÍAZ, A. y BESCÓS, A., 2001: Tiermes V. Carratiermes necrópolis celtibérica. Campañas 1977 y 1986-1991. (Arqueología en Castilla y León. Memorias, 9). Valladolid.

BARRIENTOS, J., 1935-36: "Sobre la antigua Cauca”, BSAA (Fascs. XI-XII), 141-142 y Láms. 27-31 (I-V). Valladolid.

BARRIO MARTÍN, J., 1994: "Las manifestaciones plásticas entre los pueblos de cultura celtibérica en las tierras de Segovia", Estudios Segovianos, 91, 397-427. Segovia.

- 1999: La Segunda Edad del Hierro en Segovia (España). Estudio arqueológico del territorio y la cultura material de los pueblos prerromanos. (BAR, Int. Ser., 790). Oxford.

BEIRÃO, C. M., SILVA, C. T. da, SOARES, J., GOMES, M. V. y GOMES, R. V., 1985-86: “Um depósito votivo da II Idade do Ferro, no sul de Portugal, e as suas relações com as culturas da Meseta”, en J. Gorrochategui, J. L. Melena y J. Santos (eds.) Studia Palaeohispánica. Actas del IV Coloquio sobre Lenguas y Culturas Paleohispánicas, (Veleia, 2-3), 207-221. Vitoria.

BENÍTEZ DE LUGO, L., ESTEBAN, G. y HEVIA, P., 2004: Protohistoria y Antigüedad en la provincia de Ciudad Real (800 a. C.-500 d. C.). Ciudad Real.

BLANCO GARCÍA, J. F., 1992: "El complejo alfarero vacceo de Coca (Segovia)", Revista de Arqueología, 130, 34-41. Madrid.

- 1994: "El castro protohistórico de la Cuesta del Mercado (Coca, Segovia)", Cuadernos de 
Prehistoria y Arqueología de la Universidad Autónoma de Madrid, 21, 35-80. Madrid.

- 1998a: "La Edad del Hierro en Sepúlveda", Zephyrus, LI, 137-174. Salamanca.

- 1998b: "Las producciones cerámicas del alfar vacceo de Cauca (Coca, Segovia)", Madrider Mitteilungen, 39, 121-141. Mainz.

- 2006: "El paisaje poblacional segoviano en época prerromana: ocupación del territorio y estrategias de urbanización", Oppidum. Cuadernos de Investigación, 2, 35-84. Segovia.

BRONCANO, S. y BLÁNQUEZ, J., 1985: El Amarejo (Bonete, Albacete). (EAE $\left.\mathrm{n}^{\circ} 139\right)$. Madrid.

CABRÉ, E., 1988: "Espadas y puñales de la meseta oriental en la II Edad del Hierro", en F. Burillo, J. A. Pérez y M. L. de Sus (coms.) Celtíberos. Catálogo de la Exposición (Zaragoza, 1988), 123126. Zaragoza.

- 1990: "Espadas y puñales de las necrópolis celtibéricas", en F. Burillo (coord.) II Simposio sobre los Celtíberos. Necrópolis Celtibéricas, 205-224. Zaragoza.

CATLING, H. W., 1964: Cypriot Bronzework in the Mycenean World. Oxford.

CHAPA, T., 2003: "La percepción de la infancia en el mundo ibérico", Trabajos de Prehistoria, 60 (n ${ }^{\circ}$ 1), 115-138. Madrid.

CURCHIN, L. A., 2004: The Romanization of Central Spain. Complexity, Diversity and Change in a Provincial Hinterland. (Routledge). London and New York.

ESPARZA ARROYO, A., 1988: "Materiales de la Edad del Hierro", en La Colección Arqueológica del Padre Saturio González en Santo Domingo de Silos, 115-158. Burgos.

FERNÁNDEZ, F., CHASCO, R. y OLIVA, D., 1979: Excavaciones en 'El Cerro Macareno'. La Rinconada. Sevilla. (Cortes E-F-G. Campaña 1974). Noticiario Arqueológico Hispánico, 7, 793. Madrid.

GARCÉS i ESTALLO, I., 1993: “Terracotas femeninas de aspecto ibérico en Cataluña y Aragón”, Pyrenae, 24, 207-226. Barcelona.

GARCÍA CANO, J. M., 1997: Las necrópolis ibéricas de Coímbra del Barranco Ancho (Jumilla. Murcia). I. Las excavaciones y estudio analítico de los materiales. Murcia.

GARCÍA CANO, J. M., PAGE, V., GALLARDO, J. y RAMOS, F., 2008: El mundo funerario ibérico en el altiplano Jumilla-Yecla (Murcia): la necrópolis de El Poblado de Coímbra del Barranco Ancho. Investigaciones de 1995-2004. II.- Las incineraciones y los ajuares funerarios. Murcia.

GIL FARRÉS, O., 1951: “Dos interesantes piezas prehistóricas del Museo Arqueológico Nacional”, Estudios Segovianos, 8, 217-222. Segovia.

JIMENO MARTÍNEZ, A., 2005: Celtíberos. Tras la Estela de Numancia. Catálogo de la Exposición (Soria, 2005). Soria.

JIMENO MARTÍNEZ, A. et alii, 2004: La Necrópolis Celtibérica de Numancia. (Arqueología en Castilla y León. Memorias, 12). Soria.

JUAN I MOLTÓ, J., 1987-88: "El conjunt de terracotes votives del santuari ibèric de la Serreta (Alcoi, Cocentaina, Penàguila)", Saguntum-Papeles del Laboratorio de Arqueología de Valencia, 21, 295329. Valencia.

LÓPEZ AMBITE, F., 2008: "Poblamiento y fronteras durante el periodo Celtibérico Pleno y Tardío en la zona nordeste de la provincia de Segovia: el surgimiento de las ciudades y su destrucción", BSAA arqueología, LXXIV, 75-148. Valladolid.

LORRIO, A., 1997: Los celtíberos. (Complutum. Extra, 7). Alicante-Madrid.

MARCO SIMÓN, F., 1987: "La religión de los celtíberos", en F. Burillo (coord.) I Simposium sobre los Celtíberos, 55-74. Zaragoza.

MÉLIDA, J. R., 1922: Excursión a Numancia pasando por Soria y repasando la historia y la antigüedades numantinas. Madrid.

MOLINA, J., MOLINA, M. C. y NORDSTROM, S., 1976: Coímbra del Barranco Ancho (JumillaMurcia). Serie de Trabajos Varios del S.I.P., vol. 52. Valencia.

MONEO, T., 2003: Religio Ibérica. Santuarios, ritos y divinidades (Siglos VII - I A.C.). (Bibliotheca Archaeologica Hispana, 20). Madrid.

MORENA LÓPEZ, J. A., 1989: El santuario ibérico de Torreparedones (Castro del Río - Baena, Córdoba). Estudios Cordobeses, 46. Córdoba.

PAGE, V., GARCÍA, J. M., INIESTA, A. y RUIZ, M. J., 1987: 10 años de excavaciones en Coímbra del Barranco Ancho. Jumilla. Murcia.

ROMERO CARNICERO, F., 1991: “El artesanado y sus creaciones", en M. Almagro-Gorbea (coord.) Los Celtas en la Península Ibérica. (Revista de Arqueología. Extra, 5), 82-91. Madrid.

SAADÉ, G., 1979: Ougarit. Metropole cananéene. Beirut. 
SALINAS DE FRÍAS, M., 1984-85: "La religión de los celtíberos (I)", Studia Histórica, II-III, n 1 , 81-102. Salamanca.

- 1985: "La religión indígena de la Hispania central y la conquista romana", Studia Zamorensia, VI, 307-331. Zamora.

SÁNCHEZ MESEGUER, J. L. y QUESADA SANZ, F., 1991: "La necrópolis ibérica del Cabecico del Tesoro (Verdolay, Murcia)", en J. Blánquez y V. Antona (coords.) Congreso de Arqueología Ibérica: las Necrópolis. (Universidad Autónoma de Madrid. Serie Varia, 1), 349-396. Madrid.

SANZ MÍNGUEZ, C., 1997: Los Vacceos: cultura y ritos funerarios de un pueblo prerromano del valle medio del Duero. La necrópolis de Las Ruedas, Padilla de Duero (Valladolid). Junta de Castilla y León. (Arqueología en Castilla y León. Memorias, 6). Salamanca.

SCHÜLE, W., 1969: Die Meseta-Kulturen der Iberischen Halbinsel. Mediterrane und Eurasische Elemente in Früheisenzeitlichen
Kulturen Südwestereuropas. Madrider Forschungen, 3. 2 vols. Berlín.

SOPEÑA GENZOR, G., 1987: Dioses ética y ritos. Aproximaciones para una comprensión de la religiosidad entre los pueblos celtibéricos. Zaragoza.

TARACENA, B. de, 1932: Excavaciones en la provincia de Soria. (MemJSEA, 119). Madrid.

- 1954: “Los pueblos celtibéricos", en HEMP, I (3), 195-299. Madrid.

VILASECA, S., 1947: "Dos figuritas de barro del poblado ibérico de Serra d'Espasa, de Capsanes, provincia de Tarragona", Crónica del II Congreso Arqueológico del Sureste Español, 259-264. Albacete.

WATTENBERG, F., 1963: Las cerámicas indígenas de Numancia. (Bibliotheca Praehistorica Hispana, IV). Madrid.

- 1965: "Algunas notas sobre formas y características de la cerámica vaccea”, BSAA, XXXI, 5-14. Valladolid 